\title{
Chemical Composition, Antioxidant Activity and Cytotoxicity of Essential Oil of Mentha viridis
}

\author{
Hiba A Hassan ${ }^{1}$, Ahmed S Kabbashi ${ }^{2}$, Ali Abedallah ${ }^{3}$ Vitthal D Wagh ${ }^{4}$ and Omer Abdalla Ahmed Hamdi ${ }^{14 *}$ \\ ${ }^{1}$ Department of Chemistry, Faculty of Science and Technology, Al-Neelain University, Khartoum, Sudan \\ ${ }^{2}$ Medicinal and Aromatic Plants and Traditional Medicine Research Institute (MAPTMRI), National Center for Research, Khartoum, Sudan \\ ${ }^{3}$ College of Pharmacy, Sudan University of Science and Technology, Sudan \\ ${ }^{4}$ Graduate Institute of Natural Products, College of Pharmacy, Kaohsiung Medical University, Kaohsiung, Taiwan
}

*Corresponding Author: Omer Abdalla Ahmed Hamdi, Department of Chemistry, Faculty of Science and Technology, Al-Neelain University, Khartoum, Sudan.

Received: June 18, 2019; Published: July 31, 2019

DOI: $10.31080 /$ ASMS.2019.03.0368

\begin{abstract}
The current study was designed to study the chemical composition of essential oil isolated from leaves of Mentha viridis. In addition, the antioxidant activity and cytotoxicity of the isolated oil were evaluated. The oil was obtained by hydrodistillation technique and identified by Gas chromatography-mass spectrometry (GC-MS). The main compounds of the oil were acyclo-monoterpenes (25\%), cyclo-mono trepenes (15\%), monoterpenes type-alcohol (8\%), and other classes of compounds collectively are (52\%), including fatty acid esters, Vitamin E. A total of 37 compounds were identified by GC-MS analysis of the hydrodistilled oil of menthol. The major volatile components were D-Carvone (51.91\%), D-Limonene (24.64\%), Vitamin E (3.70\%), Eucalyptol (2.81\%) (-)-8-p-Menthen-2-yl, acetate Trans (2.69\%), beta-Myrcene (1.80\%), Retinol acetate (1.51\%). Antioxidant screening using 2.2Di (4-tert-octylPhenyl)-1-Picryl-Hydrazyl (DPPH), compared with propyl galate as standard antioxidant and cytotoxicity (MTT-assay) with test concentrations $(500,250$ and $125 \mu \mathrm{g} / \mathrm{mL}$ ) and Triton-100 (the reference control) was studied. The antioxidant activity gave (15 $\pm 0.135 \mathrm{RSA} \%)$ in comparison to the control of propyl galate levels $(88 \pm 0.07 \mathrm{RSA} \%)$ and MTT assay verified the safety of the examined extract.
\end{abstract}

Keywords: Gas Chromatography-Mass Spectrometry (GC-MS); Antioxidant Activity; Cytotoxicity; Mentha Viridis (Leaves) Essential Oils

\section{Introduction}

An accessible and affordable medicinal and aromatic plants which are culturally used as a source of primary healthcare [1]. Medicinal plants are currently highlighted more attention than before because they have the ability of giving lots of benefits to society indeed to human beings particularly in the field of medicine and pharmacological functions [2]. The medicinal values of these plants lies in bioactive constituents that demonstrate certain pharmacological activities on the human body [3]. Bioactive compounds are naturally occurring in plants such as medicinal plants, vegetables and fruits that display with nutrients and fibers to cure diseases or more precisely to prevent diseases [4].

Plant derived essential oils represent an important class of natural products that contributes in various domains of human activities. In nature, essential oils play important role in production of plants [5]. Essential oils are volatile, natural, complex compound mixtures characterized by strong odour. Essential oils are variable mixtures composed principally of terpenoids, including monoterpenes and sesquiterpenes [6].

Essential oils isolated from aromatic plants have recently increased popularity and scientific importance. Several plants are employed for different industrial goals such as food, drugs, and perfumery manufacturing [5]. These bioactive compounds have a wide spectrum of pharmacological actions [7]. They also do not enhance the "antibiotic resistance", a phenomenon caused by long-term use of synthetic antibiotics [8]. However, because of an increasing of herbal products usage, an intensive care should be given to their toxicity potency, and drug-drug interactions [9]. 
The Lamiaceae family is one among the biggest and most unique families of flowering plants.It consists of about 220 genera and approximately 4000 species worldwide [10]. In terms of ethno medicine, it is one of the most diverse and widespread plant families [11].

Essential oils are contained of a number of different compounds of various biosynthetic origins varying from terpenoids to compounds containing sulfur [12], and such compounds are naturally found in various concentrations [13]. The essential oils obtained from the Mentha genus display a high commercial value, because of the presence of monoterpene menthol. This menthol is extensively used in pharmaceutical, cosmetic, personal care and food products [14].

An important genus Mentha is containing about 25 to 30 aromatic herbs of hard taxonomic classification because of a great diversity in their frequent hybridization and morphological characters [11]. The aromatic Mentha herbs are perennials cultivated from damp or wet places. The species of this genus are the most producer source of essential oil in the world [15]

Mentha plants are largely used for curing of disorders of gastrointestinal tract [16]. They have also been found to some bioactivities such as anticarcinogenic, antioxidant, anti-inflammtory, analgesic and antimicrobial effects [11]. The pharmacological effects of Mentha plants are mainly due to the presence of compound groups of phenolic and essential oil compounds [17]. The main phenolic compounds are reported in Mentha species include caffeic acid derivatives and flavonoids containing glycosides such as luteolin, apigenin, eriodictyol and naringenin. However, reported results on the biological activity and chemical composition of Mentha have mostly focused on the investigation of its essential oils. Mentha plants essential oils are basically consisted of sesquiterpenoids and monoterpenoids which content has percentage composition varies [18].

Various most existent essential oils compounds of Mentha species are ketones. Carvone, often reported as a main component of M. spicata L. oil [19], has also been reported for plants like M. longifolia (L.), M. suaveolens Ehrh, M. × villosa Huds. and M. × smithiana R. Graham [17]. In addition, the cis- and trans- isomers of dihydrocarvone have been reported as major compounds of the previously mentioned Mentha plants [20]. Other more prevalent ketones are menthone, isomenthone and pulegone. In addition, 3-octanone, piperitenone and piperitone have been characterized as main components [21]. Therefore, the aims of this work were to detect the chemical components of the hydrodistilled oil of $M$. viridis by a GC-MS technique and to examine their antioxidant activity and cytotoxicity.

\section{Experimental}

M. viridis leaves were collected from Khartoum city a central of Sudan between January to February 2017. The plant was recognised and authenticated by one taxonomist from the Institute of the Medicinal, Aromatic Plants and Traditional Medicine Research (MAPTMRI) Khartoum, Sudan. Leaves of $M$. viridis were initially dried by air, under the shade then stored. The shade was in a good ventilation. The plant was finely ground in a mill and kept in the herbarium until their uses for oil obtaining. The leaves of $M$. viridis are presented in (Figure 1).

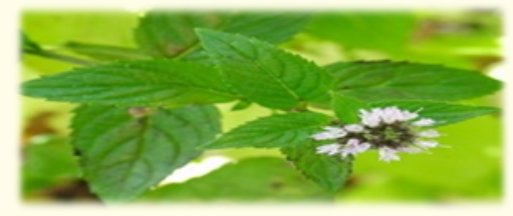

Figure 1: M. viridis (leaves).

Extraction and identification of chemical compounds of $M$. viridis

The oil of the closen $M$. viridis leaves was performed by hydrodistillation technique with Clevenger's apparatus. An amount of 100 grams from plant materials were put in a $2 \mathrm{~L}$ round bottomed flask and distilled water was added and mixed smoothly. The contents of the flask were softly boiled for approximately 4 hours until the volatile oil has been extracted. The volatile oil obtained from the plant was shifted by means of a pipette into a brown glass bottle. Small amount of an anhydrous sodium sulphate was gently added to absorb the water. The pure oil was poured into the brown glass bottle and saved in the refrigerator until needed for chemical analysis.

Shimadzu Q P2010 GC/MS (Japan) instrument GC-MS was used and fitted with reference libraries. The instrument method was as follows: the flow rate was $1 \mathrm{ml} / \mathrm{min}$ of helium as carrying gas. The temperature was programmed at $50-280{ }^{\circ} \mathrm{C}$, at rate of $8{ }^{\circ} \mathrm{C}$ / min. Mass spectrometry was taken at ionization voltage $70 \mathrm{eV}$. Library matching was done with Wiley GC-MS library. The individual identification were matched by the comparison of fragmentation patterns with those establised in the library of the mass spectrometer and literature [24].

\section{Cytotoxicity test}

Micro-culture-tetrazolium MTT-assay was applied to assess the cytotoxicity of the oil of $M$. viridis. This colorimetric assay is established by the capacity of mitochondria-succinate dehydrogenase enzymes in breathing living cells to decrease the yellow water soluble substrate 3- (4, 5-dimethyl thiazol-2-yl)-2, 
5-diphenyltetrazolium bromide (MTT) into an insoluble, blue colored-formazan, a product was spectrophotometerically measured. Since the MTT reduction can only happen in metabolically active cells, the estimation of activity is a measure of the viability of the cells [22].

\section{Cell Line and Culture Medium}

Vero (African green monkey kidney. Normal) cells were cultured in a culturing flask having a complete medium consisting of ratio of $10 \%$ fetal bovine serum and about $90 \%$ minimal essential medium (MEM) and after that incubated at $37^{\circ} \mathrm{C}$. The cells were sub cultured two times a week.

\section{Cell counting}

Cells were calculated by means of enhanced Neubauer chamber. Cleaning using detergent for the cover slip and chamber, was washed carefully with distilled water and with $70 \%$ ethanol it was swapped, then dried. To exactly equal amount of $0.4 \%$ trypan blue in a small tube was added with an aliquot of cells suspension. The chamber was stimulating with cell suspension. After cells had established, the chamber was located under light microscope. Using $40 \mathrm{X}$ objective, cells in the four large corner squares (each having 16 small squares) were totalled. The following formula was used for calculating the cells:

(Cells $/ \mathrm{ml}) \mathrm{N}=$

Number of cells counted X Dilution factor* X $10^{4}$

4

*Dilution factor is usually 2 (1:1 dilution with trypan blue), but may need to further dilute (or concentrate) cell suspensions.

\section{MTT assay}

Successive dilutions of extract were made in a 96 well flat bottomed plate (Nalge Nunc, Inter.). The outer walls of the plate were occupied with $250 \mu \mathrm{l}$ of in-complete culture medium with excluding the last row six middle wells (B - G), which were done for the negative control receiving $50 \mu \mathrm{l}$ of culture medium and $2 \mu \mathrm{l}$ of sterile $0.5 \%$. Triton X. $50 \mu \mathrm{l} /$ wells complete culture medium (CCM) were mixed and $30 \mu \mathrm{l}$ more were further added to second column wells $(B-G)$ that were used as first extract dilution wells. To the first dilution wells in the row, an amount of $500 \mu \mathrm{g}$ of $\mathrm{c}$ suspensionextractwerecarefullyadded to the $80 \mu$ l.extractwerethen sequentially diluted by two-fold dilution from well B3 till B11 by shifting $250 \mu$ l to the next well after proper adding. From the final dilution wells (B-11), 50 $\mu$ l were thrown out. Each compound was examined in triplicate. Cell suspension in a complete culture medium having $2.5 \mathrm{X} 105 / \mathrm{ml}$ was well mixed, and $150 \mu \mathrm{l}$ of it were transferred into each well of the plate. The plate was roofed and located at $37^{\circ} \mathrm{C}$ in $5 \% \mathrm{CO}_{2}$ incubator for $3-5$ days (72 hours -120 hours). On the $3^{\text {th }}-5^{\text {th }}$ day, the supernatant was removed from each well without separating cells. MTT ((3- (4, 5-Dimethylthiazol2-yl)-2,5-diphenyltetrazolium bromide, a yellow tetrazole) stock $(5 \mathrm{mg} / \mathrm{ml}$ ) was prepared earlier in $100 \mathrm{ml}$ PBS (phosphate buffer saline). MTT solution suspension was vortexed and kept on magnetic stirrer until all MTT dissolved. The clear suspension was sieved, treated with $0.2 \mu$ Millipore filter and kept at $4^{\circ} \mathrm{C}$ or 20 until use. MTT solution was diluted (1:3.5) in a culture medium and carried out at room temperature. $50 \mu \mathrm{l}$ of diluted MTT were added to each well of the 96 well plates. The plate was further incubated at $37^{\circ} \mathrm{C}$ for 2 -3 hours in $\mathrm{CO}_{2}$ incubator. MTT solution was removed carefully without detaching cells, and to each well a $200 \mu \mathrm{l}$ of DMSO were added. The plate was stressed at room temperature for 15 minutes then recorded at $540 \mathrm{~nm}$ using micro plate reader. The percentage growth inhibition was accounted using the following formula

$\%$ cell inhibition $=100-\{($ Ac-At $) / \mathrm{Ac} \times 100$

Where, At $=$ Absorbance value of test compound; $\mathrm{Ac}=$ Absorbance value of control.

\section{Antioxidant activity}

DPPH radical scavenging assay

The DPPH radical scavenging was assessed according to the method proposed by Shimada., et al. [23], with some slight modification. In 96-wells plate, the samples were undergone to react with (DPPH) for half an hour at $37^{\circ} \mathrm{C}$. The concentration of DPPH was $300 \mu \mathrm{M}$. The samples were prepared in DMSO while DPPH was dissolved in ethanol. Following incubation, decreasing in absorbance was observed at $517 \mathrm{~nm}$ using multi-plate reader spectrophotometer. Percentage radical scavenging activity by sample was assessed in comparison with a DMSO treated control group and P. gallate. All tests and analysis were done in triplicate.

\section{Statistical analysis}

All data were taken as means \pm S.D Statistical analysis for all the assays results were done using Microsoft Excel program (2016).

\section{Results and Discussion}

The yield of the oil extracted from M. viridis leaves was found to be $7.5 \%$. A total of 37 compounds were analytically elucidated in the oil isolated from $M$. viridis leaves. The chemical composition coupled with the abundance and retention time of the oil isolated from M. viridis leaves were presented in (Table 1). The major compounds of the oil were D-Carvone (51.91\%), D-Limonene (24.64\%), Eucalyptol (2.81\%), Vitamin E (3.70 \%), (-)-8-pMenthen-2-yl, acetate, trans (2.69\%), beta.-Mereene (1.80\%), Retinol, acetate (1.51\%), 2-Cyclohexen-1-ol, 2-methyl-5-(1methylethyl) (1.38\%), Biocyclo [3.1.1], hexane, 6,6-dimethyl- 
2-methylene (1.19\%) are shown in Table 1 and (Figures 2-5). Carvone-rich spearmint oil which has been found previously in India and also in other countries. previous study revealed that two major constituents which were carvone (59.6-72.4\%) and limonene (10.7-24.8\%) obtained from $M$. viridis oil at different crop stages from the mid-hills of Himalayan region of India [25]. While another study showed major constituents carvone (49.6$76.6 \%$ ) followed by limonene (9.5-22.3\%), 1,8-cineole (1.3-2.6\%) and transcarveol $(0.3-1.5 \%)$ found in $M$. viridis oil cultivated from different subtropical and temperate zones of north-west Himalayan area of India [25]. Currenly, M. viridis oil is beneficial for commercial market as it displays a range of aroma chemicals working in perfumery, flavor, pharmaceutical and other allied industries. Additionally, the major compounds in the M. viridis oil can be applied as a vital tool in other samples oil authentication from different regions.

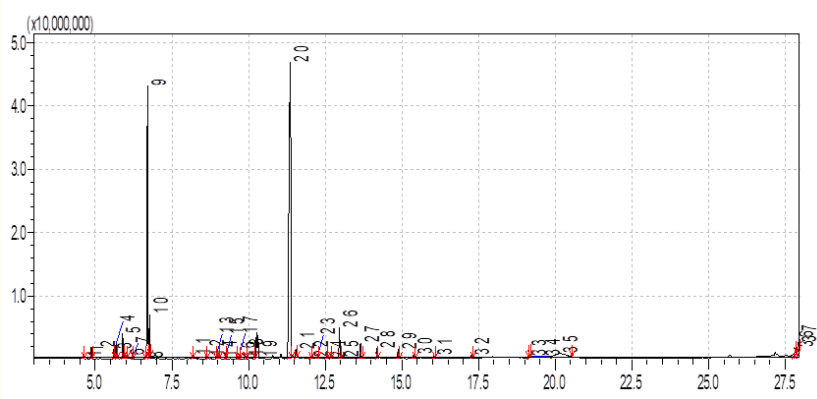

Figure 2: Gas chromatogram profile of the essential oil of $M$. viridis showing the retention time of the compounds.

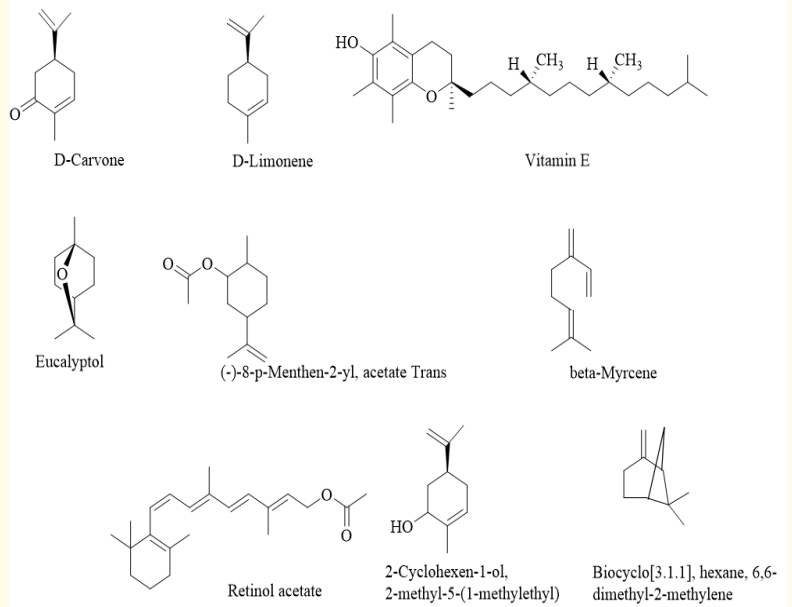

Figure 3: Chemical structures of major compounds of the essential oil from $M$. viridis.

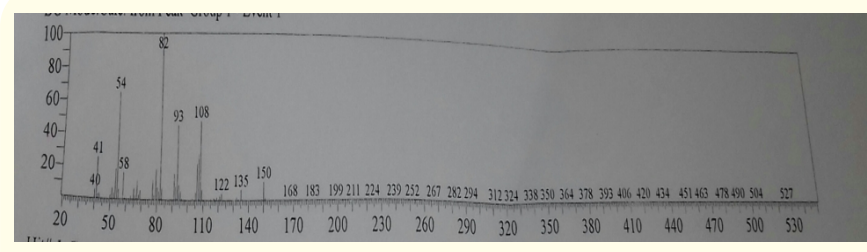

Figure 4: Mass spectrum of 2-Cyclohexane-1-one, 2-methyl-5-(1-methylethenyl).

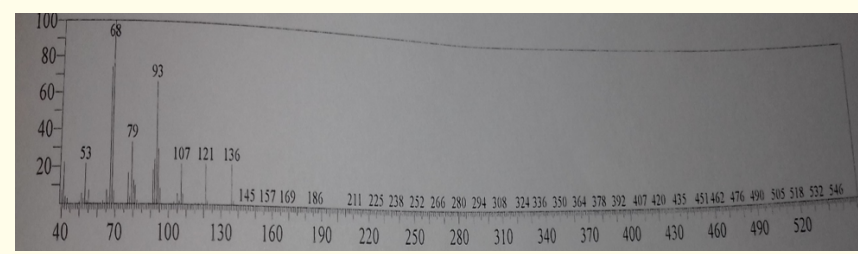

Figure 5: Mass spectrum of Cyclohexane, 1-methyl-4(1-methylethenyl).

The cytotoxicity evalution using 3- (4, 5-dimethyl thiazol2-yl)-2, 5diphenyl tetrazolium bromide (MTT assay) with three concentrations (500, 250 and $125 \mathrm{ppm}$ ) with compared with tritonx100 (the reference control). Cytotoxicity effect by using MTT-assay include (Vero cell line) was primarily conducted in this study for safety assessment use of the essential oil isolated from $M$. viridis leaves. The results obtained from the MTT assay proved the safety of the tested oil (Table 2).

\begin{tabular}{|c|c|c|c|c|c|c|}
\hline \multirow{3}{*}{ NO } & \multirow{3}{*}{$\begin{array}{c}\text { Name of } \\
\text { oil }\end{array}$} & \multirow{2}{*}{\multicolumn{3}{|c|}{$\begin{array}{c}\text { Concentrations }(\mu \mathrm{g} / \\
\mathrm{ml})\end{array}$}} & \multirow{3}{*}{$\begin{array}{l}\mathrm{IC}_{50} \\
(\mu \mathrm{g} / \\
\mathrm{ml})\end{array}$} & \multirow{3}{*}{ IC $_{50}$} \\
\hline & & & & & & \\
\hline & & 500 & 250 & 125 & & \\
\hline 1 & M. viridis & $\begin{array}{c}70.0 \pm \\
0.08\end{array}$ & $\begin{array}{c}53.0 \pm \\
0.09\end{array}$ & $\begin{array}{c}40.0 \pm \\
0.02\end{array}$ & 204.9 & $>100$ \\
\hline 2 & ${ }^{*}$ Control & \multicolumn{4}{|c|}{$96.28 \pm 0.01$} & $<30$ \\
\hline
\end{tabular}

Table 2: Cytotoxicity of $M$. viridis on normal cell lines (Vero cell line) as measured by the MTT assay:

Key: IC50 < $30 \mu \mathrm{g} / \mathrm{ml}$ : high toxic, $>100 \mu \mathrm{g} / \mathrm{ml}$ : no toxic ${ }^{*}$ Control $=$ Triton-x100 was used as the control positive at $0.2 \mu \mathrm{g} / \mathrm{mL}$.

Antioxidants are tremendously important substances which possess the ability to protect the body from damage caused by free radical induced oxidative stress. The antioxidant activity of 
the $M$. viridis oil was investigated in the search for new bioactive compounds from natural resources. As shown in Table 2, the results of antioxidant activity of essential oil of $M$. viridis (leaves) showed antioxidant activity against the DPPH free radical $(15 \pm$ $0.135 \mathrm{RSA} \%$ ). Table 2 indicates the anti DPPH of essential oil of $M$. viridis (leaves) the reading and propyl gallate was used as standard drug level. The tested antioxidant activity gave (15 \pm 0.135 RSA \%) in comparison to the control of propyl galate levels gave ( $88 \pm 0.07$ RSA \%) (Table 3).

\begin{tabular}{|l|c|c|}
\hline No & Name of Oil & \%RSA $^{*} \pm$ SD (DPPH) \\
\hline 1 & M. viridis & $15 \pm 0.135$ \\
\hline 2 & ${ }^{*}$ Control & $88 \pm 0.07$ \\
\hline
\end{tabular}

Table 3: Antioxidant activity of $M$. viridis (oil) extract: Key: RSA* = Radicals scavenging activity, ${ }^{*}$ Control $=$ P.G $=$ propyl galate .

Mint plant are one of the most interesting research plants. They are between aromatic plants and medicinal plants. There is numerous research on mint. However, only few reports are available on the Physicochemical Properties of Spearmint Oil in Sudan.

Mint essential oil contains: Acid value (1.1 mg), Ester Value (7.312 mg), Density (0.8062 mg), Iodine value (66.05 mg) and Refractive Index (1.485 mg) (Table 4).

\begin{tabular}{|l|c|c|}
\hline No & Test & Value \\
\hline 1 & Acid Value & 1.1 \\
\hline 2 & Ester Value & 7.312 \\
\hline 3 & Density & 0.8062 \\
\hline 4 & Iodine Number & 66.05 \\
\hline 5 & Refractive Index & 1.485 \\
\hline
\end{tabular}

Table 4: Results of some selected physiochemical test for the essential oil of menthol.

\section{Conclusion}

The oil isolated from $M$. viridis leaves by hydrodistillation and its antioxidant analysis was assessed by DPPH-assay method. The medicinally important components are in the form of the oil which yielded about $1.75 \%$ of the leaves. The present study showed that the major compounds found in the oil M. viridis are carvone and limonene. From the results obtained, it can be concluded that the active compounds found in the oil of $M$. viridis L. should definite- ly apply for curing various cancer infections. Doing more studies on the essential oils in order to know the physical and chemical properties. In order to take advantage of the chemical components used in the medical and industrial field.

\section{Acknowledgements}

We would like to thank Scientific Research and Innovation, Ministry of Higher Education and Scientific Research, Sudan for financial support of this work with giving grant.

\section{Bibliography}

1. Kalita P., et al. "An overview and future scope on traditionally used herbal plants of Assam having Antidiabetic activity". International Journal of Advances in Pharmacy, Biology and Chemistry 3.2 (2014): 299- 301.

2. Awasthi A., et al. "Qualitative and quantitative phytochemical screening of different plant parts of phyllanthus amarus Schum. and Thonn. collected from central India with respect to the traditional claims for their medicinal uses". International Journal of Pharmaceutical Sciences and Research 6 (2015): 393.

3. James $\mathrm{O}$ and Sunday AB. "Evaluation of acute dermal irritation and wound contraction by Gymnema sylvestre and Datura metel extracts in rats". American Journal of Biomedical and Life Sciences 2.4 (2014): 83-88.

4. Gupta C and Prakash D. "Phytonutrients as therapeutic agents". Journal of Complementary and Integrative Medicine 11.3 (2014): 151-169.

5. Cseke LJ., et al. "Natural products from plants". CRC press (2016).

6. Božović M., et al. "Mentha suaveolens Ehrh. (Lamiaceae) essential oil and its main constituent piperitenone oxide: biological activities and chemistry". Molecules 20.5 (2015): 8605-8633.

7. Brown ED and Wright GD. "Antibacterial drug discovery in the resistance era”. Nature 529.7586 (2016): 336-343.

8. Baym M., et al. "Multidrug evolutionary strategies to reverse antibiotic resistance". Science 351.6268 (6268): aad3292.

9. Braun L and Cohen M. "Herbs and Natural Supplements". Volume 2: An Evidence-Based Guide: Elsevier Health Sciences (2014). 
10. Sadeghi Z., et al. "A review on its ethnopharmacology, phytochemistry, and pharmacology". Avicenna journal of phytomedicine 4 (2014): 79.

11. Ouakouak H., et al. "Chemical composition, antioxidant activities of the essential oil of Mentha pulegium L, South East of Algeria”. International Letters of Natural Sciences 39 (2015): 49-55.

12. Peñuelas J., et al. "Biogenic volatile emissions from the soil". Plant, cell and environment 37.8 (2014): 1866-1891.

13. Seinfeld JH and Pandis SN. "Atmospheric chemistry and physics: from air pollution to climate change". John Wiley and Sons (2016).

14. Gaurav N. "An Experimental TextBook on Phytochemical Analysis and Antimicrobial Activity of Mentha Piperita". Onlinegatha (2016).

15. Nuzhat $\mathrm{T}$ and Vidyasagar G. "Antifungal investigations on plant essential oils. A review". International Journal of Pharmacy and Pharmaceutical Sciences 5 (2013): 19-28.

16. Adel M., et al. "Effects of dietary peppermint (Mentha piperita) on growth performance, chemical body composition and hematological and immune parameters of fry Caspian white fish (Rutilus frisii kutum)". Fish and Shellfish Immunology 45.2 (2015): 841-847.

17. Kapp K. "Polyphenolic and essential oil composition of Mentha and their antimicrobial effect". (2015).

18. Balla OY., et al. "Chemical Composition and Antimicrobial Activity of Essential Oil of Mentha viridis". Biochemistry and Molecular Biology 2.5 (2017): 60-66.

19. Cirlini M., et al. "Phenolic and volatile composition of a dry spearmint (Mentha spicata L.) extract". Molecules 21.8 (2016): 1007.

20. Retta DS., et al. "Essential oils of native and naturalized Lamiaceae species growing in the Patagonia region (Argentina)". Journal of Essential Oil Research 29.1 (2017): 64-75.

21. Brahmi F., et al. "Chemical composition and in vitro antimicrobial, insecticidal and antioxidant activities of the essential oils of Mentha pulegium L. and Mentha rotundifolia (L.) Huds growing in Algeria". Industrial Crops and Products 88 (2016): 96-105.

22. Patel S., et al. "In-vitro cytotoxicity activity of Solanum nigrum extract against Hela cell line and Vero cell line". International Journal of Pharmacy and Pharmaceutical Sciences 1.1 (2009): 38-46.

23. Shimada K., et al. "Antioxidative properties of xanthan on the autoxidation of soybean oil in cyclodextrin emulsion". Journal of agricultural and food chemistry 40.6 (1992): 945-948.

24. Winstock AR., et al. "Ecstasy pill testing: harm minimization gone too far?". Addiction 96.8 (2001) 1139-1148.

25. Chanotiya CS. Rajendra C. Padalia1*, Ram S. Verma1, Amit Chauhan1, Velusamy Sundaresan2 and.

\section{Volume 3 Issue 8 August 2019}

(C) All rights are reserved by Omer Abdalla Ahmed Hamdi., et al. 